\title{
Effect of combined long-term starvation and y-irradiation on membrane fatty acids and cell surface hydrophobicity of Salmonella enterica serovar Typhimurium
}

\author{
Rihab Lagha, ${ }^{*}$ Fethi Ben Abdallah, ${ }^{* 1}$ and Ahmed Salaheddine Masmoudi $\dagger$ \\ *Laboratory of Genetic, Biodiversity and Valorization of Bio-Resources, Higher Institute of Biotechnology, Monastir 5000, Tunisia \\ †Higher Institute of Biotechnology, Sidi Thabet 2020, Tunisia
}

\section{ABSTRACT}

This study was carried out to explore the adaptive mechanisms of Salmonella enterica serovar Typhimuri$\mathrm{um}$, in particular the implication of fatty acids (FA) in the remodeling of membrane lipid composition to overcome the combined effects of long-term starvation and $\gamma$-irradiation stresses. In addition, cell surface hydrophobicity was also evaluated. The bacterial strains (control and starved) were treated with a nonlethal $\gamma$-irradiation dose of $0.5 \mathrm{kGy}$ and sublethal doses of 1 kGy. Gas chromatography analysis showed that the FA composition of starved and $\gamma$-irradiated cells was modified. However starvation combined with $\gamma$-irradiation induced more modifications in the FA composition than $\gamma$-irradiation or starvation alone. Indeed, the unsaturated FA-to-saturated FA ratio decreased significantly for both strains compared with $\gamma$-irradiated cells, as main consequence of the cyclic FA formation. Our results showed that starvation, irradiation, or combined stresses significantly influenced the hydrophobicity, and this may have affected the virulence state of Salmonella Typhimurium cells. This study represents one of the few to demonstrate the modifications on bacterial membrane as a cellular response to survive to the ionizing radiation combined with long-term starvation stress.

Key words: Salmonella Typhimurium, long-term starvation, $\gamma$-irradiation, hydrophobicity, fatty acids

\section{INTRODUCTION}

Environmental stress and food preservation methods are known to induce adaptive responses within the bacterial cell. Microorganisms that survive a given stress often gain resistance to that stress or other stresses via cross-protection. The physiological state of a bac-

Received June 18, 2015.

Accepted July 28, 2015.

${ }^{1}$ Corresponding author: fetyben@yahoo.fr terium is an important consideration when studying its response to food preservation technique (Wesche et al., 2009). Current trends toward improvement in safety, quality, and convenience of foods and saving energy in food processing and distribution have increased the interest in developing new combinations of methods for food preservation. Applying combined treatments or stresses with irradiation technology consist of reducing the irradiation doses required to kill pathogenic bacteria or reducing overall microbial load (Caillet et al., 2006; Parker et al., 2010).

In many cases, the physiological effects of single stress or preservatives are reasonably well understood, but the physiological bases of the successful combination techniques have still hardly been studied. Therefore, it is important to obtain more information about the physiological bases of synergistic systems that are already empirically applied or that have future potential (Gould et al., 1995).

Salmonella is a facultative intracellular pathogen that is responsible for food-borne diseases (Finlay and Falkow, 1989). This organism is problematic for the food production industry due to its ubiquitous distribution in nature and its tolerance to various stresses. It is an enteric bacteria widely disseminated in marine environments and is challenged by a combination of hostile conditions threatening its viability (Rozen and Belkin, 2001). The most prominent stress factor in seawater and implicated in the induction of several groups of genes was nutrient limitation or starvation (Rozen et al., 2002). The starvation-stress response (SSR) of Salmonella Typhimurium encompasses the genetic and physiological realignments that occur when an essential nutrient becomes limiting for bacterial growth. The function of the SSR is to produce a cell capable of surviving long-term starvation (Spector, 1998).

Bacteria in nutritionally deficient environments are likely to integrate cell density and starvation stress signals to affect cell surface modifications and utilization of alternate energy sources (Lazazzera, 2000). Cell surface properties, including cell hydrophobicity and 
membrane fluidity as affected by FA composition, can be altered through exposure to various environmental stresses including cold, heat acid, and starvation (Moorman et al., 2008). The bacterial membrane could be identified as an important target of applied stresses combinations. The lipid composition of microorganisms can display considerable variations with changes in chemical and physical properties of the environment (Hazel and Williams, 1990; Sajbidor, 1997). The coordinate regulation of FA degradation and a protein required for general stress resistance suggested that FA or phospholipid metabolism may have a broader role in SSR than the mere utilization of FA as carbon or energy sources (Spector, 1998).

To our knowledge, no one has described the combined effects of starvation and irradiation treatment on FA and hydrophobicity of Salmonella. In addition, we are unaware of reports demonstrating how these stresses may act together to modify the bacterium cell membrane. Thereby, the main objectives of the present work were (1) to investigate the effect of sublethal ionizing radiation dose on membrane properties of Salmonella, and (2) to study some elements of the underlying physiological mechanisms of combined stress (long-term starvation and $\gamma$-irradiation) effects by determining the changes in FA composition and cell surface hydrophobicity.

\section{MATERIALS AND METHODS}

\section{Bacterial Strains}

Salmonella Typhimurium ATCC 14028s (S1) and Salmonella Typhimurium LT2 DT104 (S2), provided from French Food Safety Agency (Maisons-Alfort Cedex), were used in our study. These 2 species are part of Salmonella enterica subspecies I, which colonizes mammals and birds and causes $99 \%$ of Salmonella infections in humans. All strains were maintained at $-80^{\circ} \mathrm{C}$ in Luria-Bertani broth (Sigma-Aldrich, St. Louis, MO) supplemented with glycerol $(15 \%$, vol/vol).

\section{Starvation Stress}

For the experiments, bacterial cells were grown at $37^{\circ} \mathrm{C}$ in tryptic soy broth (Pronadisa, Madrid, Spain) for $24 \mathrm{~h}$. The microcosms, natural seawater $(100 \mathrm{~mL})$, were filtered through membranes (pore size $0.22 \mu \mathrm{m}$; Millipore, Bedford, MA) and autoclaved $\left(121^{\circ} \mathrm{C} / 20\right.$ min) in 250-mL Erlenmeyer flasks (Thermo Fisher Scientific, Waltham, MA). Salmonella Typhimurium cells were washed 3 times by centrifugation $(15,682 \times g$ for $10 \mathrm{~min}$ at $20^{\circ} \mathrm{C}$ ) with autoclaved seawater and then suspended in $10 \mathrm{~mL}$ of autoclaved seawater. The micro- cosms $(100 \mathrm{~mL})$ were inoculated with these suspensions $\left(10^{9} \mathrm{cfu} / \mathrm{mL}\right)$ and then incubated at room temperature for $3 \mathrm{yr}$ under static conditions. Three microcosms were used for each strain and 1 microcosm without bacteria was served as negative control. All the experiments were performed, in triplicate, with stressed and nonstressed bacteria. Starved cells were confirmed by PCR using SipA gene (Lagha et al., 2014).

\section{y-Irradiation Treatment}

Salmonella Typhimurium-tested strains were cultivated at $37^{\circ} \mathrm{C}$ in tryptic soy broth. The cultures grown to late $\log$ phase were divided into $1-\mathrm{mL}$ aliquots without change of broth and were exposed, in triplicate, on ice to a ${ }^{60}$ Cobalt $\gamma$-irradiator (point source, AECL, IR-79; Technopole, Sidi Thabet, Tunisia). The applied dose was 0.5 and $1 \mathrm{kGy}$ representing a nonlethal and sublethal dose, respectively. The irradiated strains were diluted 50 fold using $50 \mathrm{~mL}$ of fresh medium and then harvested after $24 \mathrm{~h}$ of incubation at $37^{\circ} \mathrm{C}$ with shaking.

\section{Analysis of FA}

To analyze the total cellular FA, Salmonella Typhimurium cells recovered from $10 \mathrm{~mL}$ of each cell suspension were pretreated following the MIDI protocols (Sasser 1990). All reagents for saponification, methylation, extraction, and washing were dispensed with autopipets into the same tube, making the hands-on time minimal. Next, the final extracts were analyzed by GC (column $=30 \mathrm{~m} \times 0.25 \mathrm{~mm}$, HP-Innowax; flame ionization detection temperature $=280^{\circ} \mathrm{C}$; carrier gas $=\mathrm{N}_{2}$ at $1 \mathrm{~mL} / \mathrm{min}$; injector temperature $=270^{\circ} \mathrm{C}$; oven temperature programmed from 130 to $230^{\circ} \mathrm{C}$ ) using a Hewlett-Packard HP 5890 capillary gas chromatograph linked to an HP Chemstation integrator (HewlettPackard, Palo Alto, CA). The identification of FAME was performed by external standards (all purchased from Sigma-Aldrich, St. Louis, MO) submitted to the same processes of manipulation as the analyzed biological samples. A known quantity of heneicosanoic acid methyl ester (C21:0) was used as an internal injection standard. The values of FA are presented as area percentage of total FA. Total SFA, total unsaturated fatty acids (UFA), and total cyclic fatty acids (CFA) were used to determine the differences among membrane FA of Salmonella Typhimurium cells grown under the different conditions.

\section{Cell Surface Hydrophobicity}

Hydrophobicity was measured by the hexadecane partitioning method of van Loosdrecht et al. (1987). 
Stressed and control bacterial cells were grown overnight in tryptic soy broth, washed 3 times by centrifugation at $3,340 \times g$ for 10 min at room temperature with PBS to remove the broth residues, then resuspended in $4 \mathrm{~mL}$ of PBS, and the absorbance (optical density at $540 \mathrm{~nm}$, $\mathrm{OD}_{540}$ ) was determined.

One milliliter of hexadecane was added to each cell suspension and vortexed for $5 \mathrm{~min}$. Each suspension was reincubated at $37^{\circ} \mathrm{C}$ for $30 \mathrm{~min}$. The aqueous layer was removed and aerated to remove all traces of hexadecane and absorbance $\left(\mathrm{OD}_{540}\right)$ was measured against a hexadecane extracted PBS blank. The hydrophobicity index was expressed as the ratio of absorbance of the hexadecane-extracted sample to absorbance of the sample before extraction.

\section{Statistical Analysis}

Statistical analysis was performed using the SPSS 13.0 statistics package for Windows (SPSS Inc., Chicago, IL). The Friedman test, followed by the Wilcoxon signed ranks test were used to examine differences in the degree of adhesion assay, in the CFA and UFAto-SFA ratio. Those $P$-values $<0.05$ were considered significant.

\section{RESULTS}

\section{Changes in FA Composition}

Starvation, $\gamma$-irradiation, and their combination were assessed for their effect on the membrane FA profiles of Salmonella Typhimurium. The FA composition of Salmonella Typhimurium is shown in Tables 1 and 2 . Seventeen FA were identified, the main ones being palmitoleic acid (C16:1n-7), palmitic acid (C16:0), oleic acid (C18:1n-9), vaccenic acid (C18:1n-7), and linoleic acid (C18:2n-6). Their percentages were between 4 and $36 \%$. Twelve FA were also detected at relatively low concentrations: C10:0, C12:0, C14:0, C14:1, C15:0 iso, C15:0 anteiso, Cyc 17, C17:1, C18:0, C18:1n-7, C20:1n-9, and C20:0.

Data analysis showed that the FA composition was significantly $(P<0.05)$ influenced by all stresses applied in our study. Further, combined starvation and $\gamma$-irradiation treatment caused marked modifications on FA composition compared with starvation alone. The FA ratio (unsaturated to saturated) present in membrane were shown in Table 2. These proportions demonstrated more easily the effects of these treatments on the unsaturation level of the FA.

Our results showed a significant increase in the CFA proportion for the 2 starved and $\gamma$-irradiated strains, incubated (i) S1 $(0.5,1)$ and S2i $(0.5,1)$, at doses of 0.5

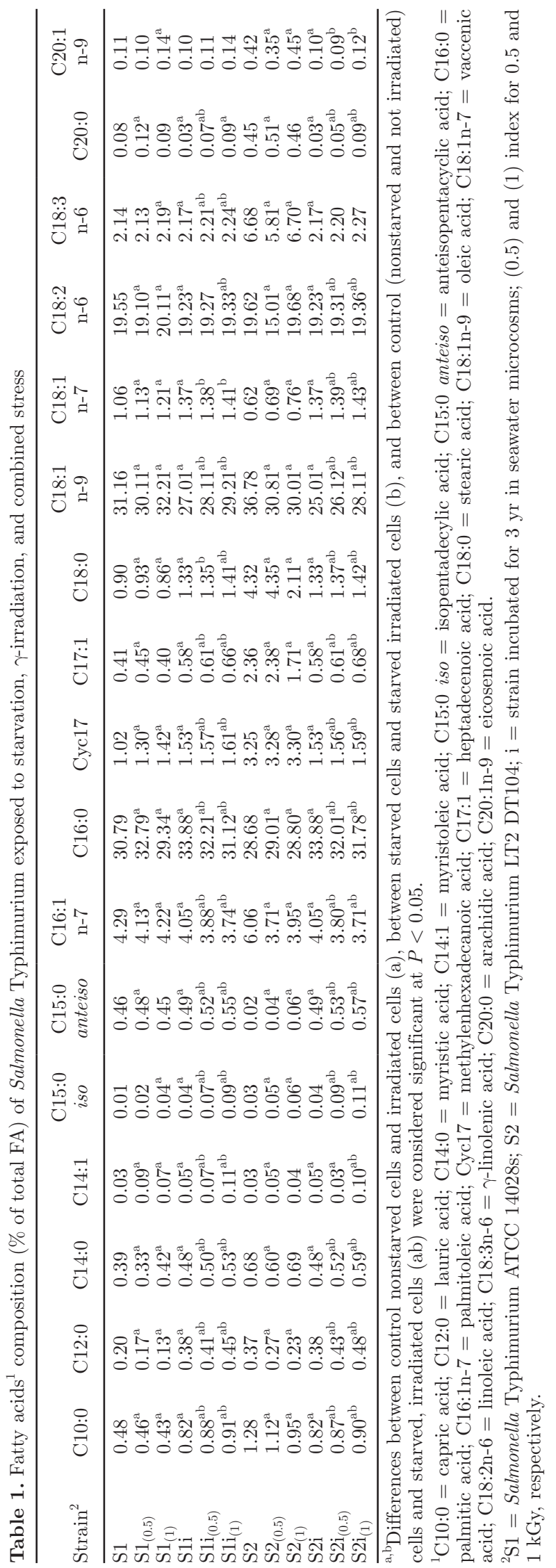

Journal of Dairy Science Vol. 98 No. 12, 2015 
and 1 kGy. Indeed, values were 1.57 and 1.61 for S1i $(0.5,1)$ and 1.56 and 1.59 for S2i $(0.5,1)$ compared to starved cells S1i and S2i (1.53 and 1.53), respectively.

In addition, the UFA-to-SFA ratio was significantly increased in both starved and $\gamma$-irradiated strains S1i $(0.5,1)$ and $\mathrm{S} 2 \mathrm{i}(0.5,1)$ at doses of 0.5 and $1 \mathrm{kGy}$ compared with starved cells S1i and S2i. Values were 1.54 and 1.61 for S1i $(0.5,1)$ and 1.49 and 1.55 for S2i $(0.5,1)$ compared to starved S1i and S2i (1.54 and $1.40)$, respectively.

At doses of 0.5 and $1 \mathrm{kGy}$, we observed a significant increase in the CFA proportion for S1 and S2 (1.30 and 1.42 , and 3.28 and 3.30 , respectively) compared with control (nontreated) cells (1.02 for S1 and 3.25 for S2). Further, the UFA-to-SFA ratio was significantly decreased in S1i $(0.5,1)$, at 1.63 and 1.89 , compared to control S2 (2.02). For Salmonella Typhimurium S1 (0.5), the ratio (1.62) was decreased but it was increased for S1 (1), to 1.90, in comparison to the nontreated strain (1.76).

By comparing the starved and $\gamma$-irradiated strains to nontreated strains, a significant decrease of the UFAto-SFA ratio was observed for S1i $(0.5,1)$, at 1.63 and 1.89 , as well as for $\mathrm{S} 2 \mathrm{i}(0.5,1)$, at 1.49 and 1.55 . In addition, the CFA values become higher in S1i $(0.5 ; 1)$, at 1.57 and 1.61, compared to S1 (1.02). However, this CFA proportion was significantly decreased for S2i $(0.5$; 1 ), at 1.56 and 1.59 , compared to S2 (3.25).

\section{Effect of Stresses on the Surface Hydrophobicity}

Starvation and $\gamma$-irradiation separately had a significant effect on the surface hydrophobicity of Salmonella Typhimurium (Table 3). The starved cells (S1i and S2i) showed a significant decrease $(P<0.05)$ in their surface hydrophobicity (26.51 and $22.22 \%$, respectively). At 0.5 and $1 \mathrm{kGy}$ doses, a significant decrease $(P<$ $0.05)$ in the surface hydrophobicity was observed for both nonstarved S1 $(0.5,1)$, at 12 and $24.13 \%$, and S2 $(0.5,1)$, at 15.33 and $19.39 \%$, compared to S1 $(28.66 \%)$ and S2 (25\%).

Combination of long-term starvation with $\gamma$-irradiation had a significant effect on this physicochemical character of Salmonella Typhimurium. Indeed, under starvation and at doses of $0.5 \mathrm{kGy}$, the surface hydrophobicity was significantly decreased for S1i (0.5), at $24.46 \%$, compared with starved S1i (26.51\%). However, at doses of $1 \mathrm{kGy}$, the hydrophobicity was increased for the same strain.

When we compared the starved and $\gamma$-irradiated strains with nontreated cells, we observed a significant decrease of hydrophobicity for S1i (0.5), but an increase for S1i $(0.1)$. For S2i $(0.5,1)$, however, the hydrophobicity was significantly decreased.
Table 2. Fatty acids ${ }^{1}$ composition ( $\%$ of total FA) of Salmonella Typhimurium under stressed conditions

\begin{tabular}{lllc}
\hline Strain $^{2}$ & SFA & UFA & UFA/SFA \\
\hline S1 & 33.31 & 58.75 & 1.76 \\
S1 $(0.5)$ & $35.3^{\mathrm{a}}$ & $57.24^{\mathrm{a}}$ & $1.62^{\mathrm{a}}$ \\
$\mathrm{S} 1_{(1)}$ & $31.76^{\mathrm{a}}$ & $60.55^{\mathrm{a}}$ & $1.90^{\mathrm{a}}$ \\
$\mathrm{S} 1 \mathrm{i}$ & $37.45^{\mathrm{a}}$ & $54.56^{\mathrm{a}}$ & $1.45^{\mathrm{a}}$ \\
$\mathrm{S} \mathrm{i}_{(0.5)}$ & $36.01^{\mathrm{ab}}$ & $55.64^{\mathrm{ab}}$ & $1.54^{\mathrm{ab}}$ \\
$\mathrm{S} \mathrm{i}_{(1)}$ & $35.15^{\mathrm{ab}}$ & $56.84^{\mathrm{ab}}$ & $1.61^{\mathrm{ab}}$ \\
$\mathrm{S} 2$ & 35.83 & $53.57^{\mathrm{a}}$ & 2.02 \\
$\mathrm{~S} 2(0.5)$ & $35.95^{\mathrm{a}}$ & $58.81^{\mathrm{a}}$ & $1.63^{\mathrm{a}}$ \\
$\mathrm{S} 2_{(1)}$ & $33.35^{\mathrm{a}}$ & $63.3^{\mathrm{a}}$ & $1.89^{\mathrm{a}}$ \\
$\mathrm{S} 2 \mathrm{i}$ & $37.45^{\mathrm{a}}$ & $52.56^{\mathrm{a}}$ & $1.40^{\mathrm{a}}$ \\
$\mathrm{S} 2 \mathrm{i}_{(0.5)}$ & $35.87^{\mathrm{b}}$ & $53.55^{\mathrm{b}}$ & $1.49^{\mathrm{ab}}$ \\
$\mathrm{S} 2 \mathrm{i}_{(1)}$ & $35.94^{\mathrm{ab}}$ & $55.78^{\mathrm{ab}}$ & $1.55^{\mathrm{ab}}$ \\
\hline
\end{tabular}

${ }^{\mathrm{a}, \mathrm{b}}$ Differences between control nonstarved cells and irradiated cells (a), between starved cells and starved irradiated cells (b), and between control (nonstarved and not irradiated) cells and starved, irradiated cells (ab) were considered significant at $P<0.05$.

${ }^{1} \mathrm{UFA}=$ total unsaturated fatty acids; UFA/SFA $=$ unsaturated-tosaturated ratio.

${ }^{2} \mathrm{~S} 1=$ Salmonella Typhimurium ATCC14028s; S2 = Salmonella Typhimurium LT2 DT104; i = strain incubated for $3 \mathrm{yr}$ in seawater microcosms; subscripts (0.5) and (1) denote 0.5 and $1 \mathrm{kGy}$, respectively.

\section{DISCUSSION}

Bacterial cytoplasmic membranes are essential for cell integrity, energy transduction, regulation of cellular growth and metabolism, stress sensing, and other vital roles (Denich et al., 2003; Edidin, 2003). Maintaining membrane integrity is therefore essential for microorganisms and any changes in this integrity are often caused by modulations in its lipid composition (Russell, 1984; Vigh et al., 1993). The results obtained in the present work for Salmonella Typhimurium showed that

Table 3. Cell surface hydrophobicity of Salmonella Typhimurium under stress conditions

\begin{tabular}{lc}
\hline Strain $^{1}$ & Hydrophobicity $(\% \pm \mathrm{SD})$ \\
\hline $\mathrm{S} 1$ & $28.66 \pm 0.2$ \\
$\mathrm{~S} 1_{(0.5)}$ & $12 \pm 0.12^{\mathrm{a}}$ \\
$\mathrm{S} 1_{(1)}$ & $24.13 \pm 0.21^{\mathrm{a}}$ \\
$\mathrm{S} 1 \mathrm{i}$ & $26.51^{*} \pm 0.15$ \\
$\mathrm{~S} \mathrm{i}_{(0.5)}$ & $24.46 \pm 0.11^{\mathrm{b}}$ \\
$\mathrm{S} 1_{(1)}$ & $32.48 \pm 0.11^{\mathrm{b}}$ \\
$\mathrm{S} 2$ & $25 \pm 0.17$ \\
$\mathrm{~S} 2(0.5)$ & $15.33 \pm 0.15^{\mathrm{a}}$ \\
$\mathrm{S} 2(1)$ & $19.39 \pm 0.14^{\mathrm{a}}$ \\
$\mathrm{S} 2 \mathrm{i}$ & $22.22^{*} \pm 0.13$ \\
$\mathrm{~S} 2 \mathrm{i}_{(0.5)}$ & $12.39 \pm 0.1^{\mathrm{b}}$ \\
$\mathrm{S} 2 \mathrm{i}_{(1)}$ & $17 \pm 0.2^{\mathrm{b}}$ \\
\hline
\end{tabular}

${ }^{\mathrm{a}, \mathrm{b}}$ Differences between control nonstarved cells and irradiated cells (a), between starved cells and starved irradiated cells (b), and between control (nonstarved and not irradiated) cells and starved, irradiated cells $(\mathrm{ab})$ were considered significant at $P<0.05$.

${ }^{1} \mathrm{~S} 1$ = Salmonella Typhimurium ATCC 14028s; S2 = Salmonella Typhimurium LT2 DT104; i= strain incubated for $3 \mathrm{yr}$ in seawater microcosms; subscripts (0.5) and (1) denote values of applied irradiation dose.

$* P<0.05$. 
this microorganism reacted differently to single stress, such as long-term starvation or $\gamma$-irradiation, compared with these 2 combined stresses.

Based on our results, it appears that starvation is the cause of changes in membrane FA composition of Salmonella Typhimurium. The decrease of the UFAto-SFA ratio mainly due to the decrease of long-chain FA (C18:1) may contribute to the membrane adaptation of Salmonella Typhimurium to starvation. In addition, Spector et al. (1999) showed that the key FA degradation enzyme, FadF (medium or long-chain fatty acylCoA dehydrogenase), is C-starvation-inducible and required for long-term C-starvation survival.

The bacterial cells regulate their lipid composition to achieve a degree of fluidity compatible with life. One of the most important consequences of membrane FA changes in microorganisms is to modulate the activity of intrinsic proteins that perform functions such as ion pumping and nutrient uptake (Russell, 1984).

Significant modifications on FA composition $(P \leq$ 0.05 ) seemed to take place after $\gamma$-irradiation treatment with a $1 \mathrm{kGy}$ dose for both strains. This behavior implies that membrane lipids play an important role in microbial adaptation to the destructive effect of the reactive oxygen species. This adaptation was related to the increase of UFA production. In this context, it's of interest to note that UFA have the ability to scavenge the reactive oxygen species. Therefore, we proposed that the modification of UFA proportions constituted an adaptive response to $\gamma$-irradiation stress in Salmonella Typhimurium. However, the response may involve the achievement of an optimum level of membrane fluidity to ensure membrane protein functions under this stress. Indeed, it was shown that DNA replication in growing Escherichia coli cells requires a fluid membrane for the DnaA protein function (Castuma et al., 1993). Ayari et al. (2009) proposed that the biosynthetic pathway by which $\gamma$-irradiated Bacillus cereus and Salmonella typhi synthesized UFA is through the action of desaturase enzyme. In this context, Guerzoni et al. (2001) assumed that the increase of an oxygen-consuming desaturase system, with a consequent increase in FA desaturation, is a cellular response to environmental stresses able to protect the cells from toxic oxygen species.

Our data clearly indicated a meaningful increase of membrane cyclic FA Cyc17 after starvation or $\gamma$-irradiation treatment with 0.5 and $1 \mathrm{kGy}$ doses for both strains, suggesting transcriptional regulation of the $c f a$ gene under this stress condition. Indeed, Grandvalet et al. (2008) reported that the level of $c f a$ transcripts increased when cells of Oenococcus oeni were grown in the presence of ethanol, at low $\mathrm{pH}$, or in nutrient depletion.
In the current study, we also showed that combined starvation and $\gamma$-irradiation stresses induced more modifications in the FA composition than the cells submitted to irradiation alone. The UFA-to-SFA ratio decreased significantly for combined stressed cells, as main consequence of the CFA formation. In bacteria, the ratio of unsaturated to saturated FA is the predominant mechanism for controlling membrane fluidity (Russell, 1984; Denich et al., 2003). However, Härtig et al. (2005) demonstrated that the presence of CFA should make the membrane more rigid because of their higher lipid melting points. Our results allowed us to suppose that long-term starvation combined with $\gamma$-irradiation enhanced the overexpression of $c f a$ gene to give more resistance against stress to the bacteria by reducing membrane fluidity. Moreover, the difference in the level of CFA between the 2 studied strains after stress exposition may be explained by a difference in the transcriptional activation of $c f a$ gene. According to Kim et al. (2005), the strategies including the construction and the physiological study of $c f a$-deficient cells in Salmonella Typhimurium demonstrated the high sensitivity of the deficient cells to acid stress.

Contrary to Ayari et al. (2009), who used the combined treatment (heat stress or carvacrol and $\gamma$-irradiation) to increase the radiosensitivity of $\mathrm{Bacil}$ lus cereus, we have shown that long-term starvation generated new adaptation strategies for Salmonella Typhimurium and created protection against the effects of radiation and probably against other types of stress. Based on our results, $\gamma$-irradiation appeared as the main cause of hydrophobicity decrease in Salmonella Typhimurium cells, and this may affect bacterial attachment to surfaces (Briandet et al., 1999) and the ability of metabolites to transit the membrane. Combined long-term starvation $\gamma$-irradiation significantly influenced hydrophobicity, and this may affect the virulence state of Salmonella Typhimurium cells. This finding correlates with other reports on Shigella strains, that the $\mathrm{pH}$ combined with starvation stress modified the surface cell hydrophobicity (Ellafi et al., 2012). According to Vesterlund et al. (2005), hydrophobicity of the bacterial cell surface is one of the most important virulence factors that contributes to the adherence of microorganisms to host tissue.

In summary, we concluded that the mode of action of combined stresses implies mechanisms of remodeling of membrane composition could overcome the stress effects of the $\gamma$-irradiation and probably create protection against other types of stress. Consequently, these findings may enable Salmonella Typhimurium to evade the lethal effects of ionizing radiation and persist in food-processing environments. The modifications of FA 
composition and cell surface hydrophobicity may, in turn, lead to the development of alternative intervention strategies for enhancing sanitizer efficacy.

\section{ACKNOWLEDGMENTS}

We are grateful to Farah Khaled, Nuclear Centre, Technopole, Sidi Thabet, Tunisia. The authors declare no conflict of interest.

\section{REFERENCES}

Ayari, S., D. Dussault, M. Millette, M. Hamdi, and M. Lacroix. 2009. Changes in membrane fatty acids and murein composition of $\mathrm{Ba}$ cillus cereus and Salmonella Typhi induced by gamma irradiation treatment. Int. J. Food Microbiol. 135:1-6.

Briandet, R., T. Meylheuc, C. Maher, and M. N. Bellon-Fontaine 1999. Listeria monocytogenes Scott A: Cell surface charge, hydrophobicity, and electron donor and acceptor characteristics under different environmental growth conditions. Appl. Environ. Microbiol. 65:5328-5333.

Caillet, S., M. Millette, S. Salmie'ri, and M. Lacroix. 2006. Combined effects of antimicrobial coating, modified atmosphere packaging, and gamma irradiation on Listeria innocua present in ready-to-use carrots Daucus carota. J. Food Prot. 69:80-85.

Castuma, C. E., E. Crooke, and A. Kornberg. 1993. Fluid membranes with acidic domains activate DnaA, the initiator protein of replication in Escherichia coli. J. Biol. Chem. 268:24665-24668.

Denich, T. J., L. A. Beaudette, H. Lee, and J. T. Trevors. 2003. Effect of selected environmental and physico-chemical factors on bacterial cytoplasmic membranes. J. Microbiol. Methods 52:149-182.

Edidin, M. 2003. Lipids on the frontier: A century of cell-membrane bilayers. Nat. Rev. Mol. Cell Biol. 4:414-418.

Ellafi, A., B. Harbi, R. Lagha, and A. Bakhrouf. 2012. The combined effects of starvation and $\mathrm{pH}$ on the virulence of Shigella sonnei ATCC25931. Afr. J. Biotechnol. 12:2034-2040.

Finlay, B. B., and S. Falkow. 1989. Salmonella as an intracellular parasite. Mol. Microbiol. 3:1833-1841.

Gould, G. W., T. Abee, P. E. Granum, and M. V. Jones. 1995. Physiology of food poisoning microorganisms and the major problems in food poisoning control. Int. J. Food Microbiol. 28:121-128.

Grandvalet, C., J. S. Assad-Garcia, S. Chu-Ky, M. Tollot, J. Guzzo, Gresti, and R. Tourdot-Marechal. 2008. Changes in membrane lipid composition in ethanol- and acid-adapted Oenococcus oeni cells: Characterization of the $c f a$ gene by heterologous complementation. Microbiology 154:2611-2619.

Guerzoni, M. E., R. Lanciotti, and P. S. Cocconcelli. 2001. Alteration in cellular fatty acid composition as a response to salt, acid, oxidative and thermal stresses in Lactobacillus helveticus. Microbiology $147: 2255-2264$.

Härtig, C., N. Loffhagen, and H. Harms. 2005. Formation of trans fatty acids is not involved in growth-linked membrane adaptation of Pseudomonas putida. Appl. Environ. Microbiol. 71:1915-1922.
Hazel, J. R., and E. E. Williams. 1990. The role of alterations in membrane lipid composition in enabling physiological adaptation of organisms to their physical environment. Prog. Lipid Res. 29:167-227.

Kim, B. H., S. Kim, H. G. Kim, J. Lee, I. S. Lee, and Y. K. Park. 2005. The formation of cyclopropane fatty acids in Salmonella enterica serovar Typhimurium. Microbiology 151:209-218.

Lagha, R., M. N. Bellon-Fontaine, M. Renault, R. Briandet, J. M. Herry, B. Mrabet, A. Bakhrouf, and M. M. Chehimi. 2014. Impact of long-term starvation on adhesion to and biofilm formation on stainless steel $316 \mathrm{~L}$ and gold surfaces of Salmonella enterica serovar Typhimurium. Ann. Microbiol. 65:399-409.

Lazazzera, B. A. 2000. Quorum sensing and starvation: Signals for entry into stationary phase. Curr. Opin. Microbiol. 3:177-182.

Moorman, M. A., C. A. Thelemann, S. Zhou, J. J. Pestka, J. E. Linz, and E. T. Ryser. 2008. Altered hydrophobicity and membrane composition on stress-adapted Listeria innocua. J. Food Prot. 71:182-185.

Parker, T. L., S. T. Esgro, S. A. Miller, L. E. Myers, R. A. Meister, S. A. Toshkov, and N. J. Engeseth. 2010. Development of an optimized papaya pulp nectar using a combination of irradiation and mild heat. Food Chem. 118:861-869.

Rozen, Y., and S. Belkin. 2001. Survival of enteric bacteria in seawater. FEMS Microbiol. Rev. 25:513-529.

Rozen, Y., R. A. Larossa, L. J. Templeton, D. R. Smulski, and S. Belkin. 2002. Gene expression analysis of the response by Escherichia coli to seawater. Antonie Van Leeuvenhoek 81:15-25.

Russell, N. J. 1984. Mechanisms of thermal adaptation in bacteria: blueprints for survival. Trends Biochem. Sci. 9:108-112.

Sajbidor, J. 1997. Effect of some environmental factors on the content and composition of microbial membrane lipids. Crit. Rev. Biotechnol. 17:87-103.

Sasser, M. 1990. Identification of bacteria by gas chromatography of cellular fatty acids. MIDI Technical Note 101. MIDI Inc., Newark, $\mathrm{DE}$

Spector, M. P. 1998. The starvation-stress response (SSR) of Salmonella. Adv. Microb. Physiol. 40:233-279.

Spector, M. P., C. C. DiRusso, M. J. Pallen, F. Garcia del Portillo, G. Dougan, and B. B. Finlay. 1999. The medium-/long-chain fatty acyl-CoA dehydrogenase (fadF) gene of Salmonella typhimurium is a phase 1 starvation-stress response (SSR) locus. Microbiology $145: 15-31$

van Loosdrecht, M. C. M., J. Van Lyklema, W. Norde, and W. Norde. 1987. The role of bacterial cell wall hydrophobicity in adhesion. Appl. Environ. Microbiol. 53:1893-1897.

Vesterlund, S., J. Paltta, M. Karp, and A. C. Ouwehand. 2005. Adhesion of bacteria to resected human colonic tissue: Quantitative analysis of bacterial adhesion and viability. Res. Microbiol. 156:238-244.

Vigh, L., D. A. Los, I. Horva'th, and N. Murata. 1993. The primary signal in the biological perception of temperature: Pd-catalyzed hydrogenation of membrane lipids stimulated the expression of the desA gene in Synechocystis, PCC 6803. Proc. Natl. Acad. Sci. USA 90:9090-9094.

Wesche, A. M., J. B. Gurtler, B. P. Marks, and T. R. Elliot. 2009. Stress, sublethal injury, resuscitation, and virulence of bacterial foodborne pathogens. J. Food Prot. 72:1121-1138. 